\title{
Postmortem computed tomography and autopsy for detection of lesions and causes of death in gunshot injury cases: a comparative study
}

\author{
Shereen Ahmad Elkhateeb ${ }^{1 *}$, Eman Bekheet Mohammed ${ }^{2}$, Hany Aziz Meleka ${ }^{1}$ and Ahmed Abd Elazeem Ismail ${ }^{3}$
}

\begin{abstract}
Background: Firearm injuries are a common cause of death in cases typically investigated by medical examiners. Postmortem multislice computed tomography (PMCT) provides valuable information that enhances the autopsy examination. This study was conducted to compare PMCT and autopsy for the detection of injuries and causes of death in cases of fatal firearm injuries. Thirty cadavers were scanned with PMCT and then underwent autopsy. The results of the two techniques were compared regarding entry wounds, wound channels, detection of foreign bodies, organ and skeletal injuries, and causes of death to determine the concordance or discordance between the two techniques.

Results: The results revealed excellent agreement between PMCT and autopsy for the detection of injuries and causes of death in cases of gunshot injury. Furthermore, PMCT revealed injuries such as pneumothorax and surgical emphysema that were found to be undetermined by autopsies where the special dissection technique was not part of our routine procedures.

Conclusion: PMCT could be a valuable complementary tool for autopsies to determine and localize injuries and causes of death in cases of gunshot injury.
\end{abstract}

Keywords: Postmortem multislice computed tomography, Autopsy, Firearm, Injuries, Causes of death, Comparative study

\section{Background}

Autopsy is the traditional means of postmortem investigation in humans. It is very important for determining the cause and manner of death (DiMaio 2002; Madea and Argo 2014). However, it is only possible to perform a complete autopsy once, and any consecutive examination will have limitations due to previous autopsy procedures, as well as changes due to decomposition or even cremation of the corpse. Furthermore, many cultures and religions do not accept mutilation of the body for the sake of autopsy (Roberts et al. 2012; Sieswerda Hoogendoorn et al. 2014).

\footnotetext{
* Correspondence: sheren_elkhateb2001@yahoo.com

'Department of Forensic Medicine \& Clinical Toxicology, Faculty of Medicine, Zagazig University, Zagazig, Egypt

Full list of author information is available at the end of the article
}

Postmortem multislice computed tomography (PMCT) has become a clinical standard and has contributed to the field of forensic autopsy with promising results. The documentation and analysis of postmortem findings with computed tomography $(\mathrm{CT})$ are investigator independent, objective, and noninvasive and will lead to qualitative improvements in forensic pathologic investigation. CT provides easy storage and transmission of data, thereby facilitating audit and review by others, and it provides images that are more suitable for court presentation than autopsy photographs. Another advantage is the ability to store the imaging data for second opinions, even years after burial (Dirnhofer et al. 2006; Simons et al. 2014; Leth 2015). Previous studies of postmortem investigations of both natural and unnatural death have shown that the diagnostic yield increases, specifically for the detection of fractures, hemorrhage, 
and gas collections, such as pneumothorax, when PMCT is performed with an autopsy (Westphal et al. 2012; Wichmann et al. 2012 Leth et al. 2013; Rutty et al. 2013; Lo Re et al. 2015) .

Regarding cases of gunshot injury, PMCT has been demonstrated to provide useful information for detecting different lesions and determining the cause of death. PMCT provides accurate illustration of body lesions, visualization of wound paths, and very accurate localization of bullets and their fragments. Moreover, PMCT can be valuable for the assessment of channels of projectiles, and in contrast to the evisceration of organs during a postmortem autopsy, PMCT allows for the evaluation of the undisturbed anatomy (Tartaglione et al. 2012; Maiese et al. 2014).

The number of scientific studies on postmortem imaging has substantially increased over time, but whether PMCT can substitute autopsy or merely act as a supplement to autopsy remains unclear. The aim of this study was to compare autopsy and postmortem PMCT regarding the detection of injuries and causes of death in cases of gunshot fatalities and to examine whether postmortem PMCT can act as an autopsy substitute or only as autopsy supplement.

\section{Materials and methods Subjects}

This study was conducted at Zagazig University Hospitals in Zagazig during the period of October 2016-July 2017. Thirty cadavers were involved in this study ( 24 males and 6 females). The age range of the cadavers was $16-55$ years. The study was performed after approval from the Institutional Review Board of the Faculty of Medicine, Zagazig University, Egypt (reference no. 1939).

\section{Inclusion criteria}

The inclusion criteria consisted of subjects with firearm injuries who were autopsied within $48 \mathrm{~h}$ postmortem.

\section{Exclusion criteria}

The exclusion criteria consisted of subjects with firearm injuries who were autopsied after $48 \mathrm{~h}$ postmortem to avoid misinterpretation of putrefaction gases and those with any surgical interference that may affect wound inlet and wound channel.

\section{Methods}

The subjects were scanned with PMCT and then underwent autopsy.

\section{Postmortem computed tomography:}

CT examinations were performed in a standardized manner with the corpses lying in a supine position (victims were kept within the body bag) on a 64-detector row CT scanner (SOMATOM Sensation Cardiac 64, Siemens Medical Solutions, Germany). The arms of the subjects were positioned alongside the body. For image analysis, axial images with a 2-mm slice thickness were reconstructed with an overlapping technique (reconstruction increment: $1 \mathrm{~mm}$ ) using standard software (Syngo B, Siemens Medical Solutions, Germany). A bone (B70f) and a soft tissue (B35f) convolution kernel were used. Images were documented in a bone window $(500 / 1500 \mathrm{HU})$ and a soft tissue window (50/350 HU). Additionally, primary coronary and sagittal multiplanar reformations (MPR) with a 4-mm slice thickness were reconstructed directly from the raw data using an overlapping technique. Images were digitally transmitted and stored in the picture archiving and communication system.

The CT images of every cadaver were interpreted by two board-certified radiologists. Their experience in reading CT scans varied from 9 to 12 years. One radiologist had previous experience in reading postmortem images. The radiologists identified entry and exit points, wound channels, and organs that were disrupted or injured. The radiologists dictated a radiology report of their findings.

\section{Autopsy}

The corpses underwent autopsy by two experienced forensic pathologists after scanning. The final report was completed by both forensic experts. The autopsy in cases of gunshot injury included the inspection of the entire skin for the entry and exit wounds followed by the opening of all three body cavities (skull, thorax, and abdomen), and the dedicated examination of all internal organs. Specimens were obtained for histology and toxicology assessments as needed.

The radiologists were blinded to the autopsy findings prior to evaluating the PMCT scans, and the forensic pathologists were blinded to the findings of all PMCT scans.

The results of both techniques were then compared as regarding entry wounds, wound channels, detection of foreign bodies, organ and skeletal injuries, and causes of death to determine the concordance or discordance between the two techniques.

\section{Statistical analysis}

Categorical data are presented as numbers and percentages. Comparisons between PMCT and autopsy findings were performed using Cohen's Kappa test (a statistical measure of agreement between two different tools for the assignment of categories). Kappa values (with 95\% confidence intervals) were calculated to determine the agreement between PMCT and autopsy for detecting different types of lesions. The values were classified as slight (0.01 to 0.30 ), fair (0.31 to 0.40$)$, moderate $(0.41$ to 0.60$)$, 
substantial (0.61 to 0.80 ), or almost perfect (0.80 to 1.00 ) agreement. The collected data were analyzed using SPSS version 16 (SPSS Inc., Chicago, IL USA) and MedCalc software.

\section{Results}

Comparison between autopsy and PMCT for gunshot injuries of the head:

Both PMCT and autopsy showed perfect agreement for detection of wound channels, entry wounds with internal beveling, and bone fragments in all 12 cases $(K(1), P<0.001)$. Regarding foreign bodies, both PMCT and autopsy detected retained bullets in 2 of 12 cases $(K$ (1), $P<0.001$; Figs. 1, 2, and 3; Table 1).

Regarding skeletal injuries, PMCT detected comminuted fractures in the vault of the skull and facial bone fracture in 8 of 12 cases, while autopsy detected these in 6 cases $(K(0.67), P<0.01$; Figs. 1 and 3; Table 1$)$. Regarding soft tissue injuries, pneumocephalus was detected by PMCT in 8 of 12 cases but was not detected by autopsy in any case $(K(0), P=1)$. Autopsy detected cerebral lacerations in 12 cases but PMCT detected lacerations in 6 cases $(K(0.51) P<0.05)$. Both autopsy and PMCT could detect hemorrhage in all cases $(K(1)$, $P<0.001$; Figs. 2 and 3; Table 1).

\section{Comparison of autopsy and PMCT for multiple gunshot injuries}

Of 18 cases, wound channels and directions were determined in 12 cases by autopsy and in 6 cases by PMCT $(K(0.51), P<0.05)$. Pneumothorax and surgical emphysema were detected by PMCT in 16 and 18 cases, respectively, but not by autopsy $(K(0), P=1)$. Multiple

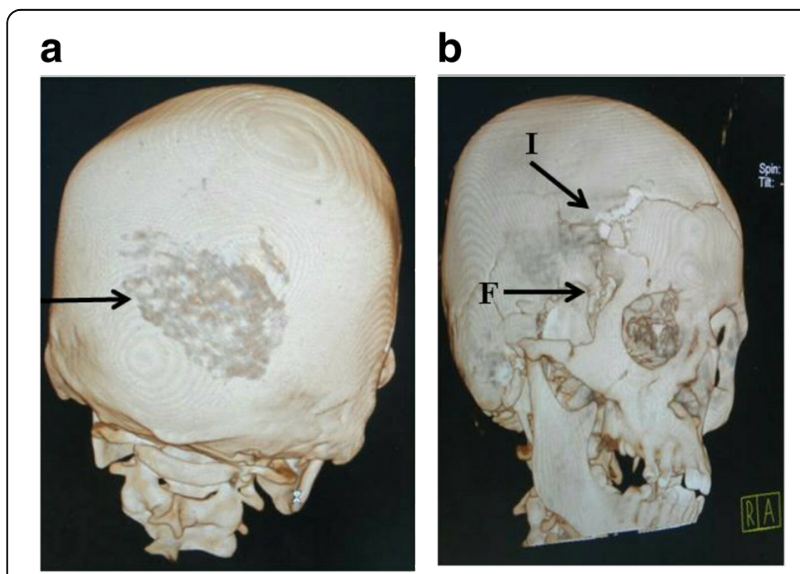

Fig. 1 Gunshot injuries of the head. a PMCT-3D-volume rendering image showing a comminuted fracture (F) opposite the exit in the occipital bone. $\mathbf{b}$ MDCT-3D-volume rendering image showing the entry wound of firearm injury $(I)$ in the right temple and multiple fractures $(F)$ of the skull bone in the right sphenoid wing, right temporal, right frontal, and right occipital bone

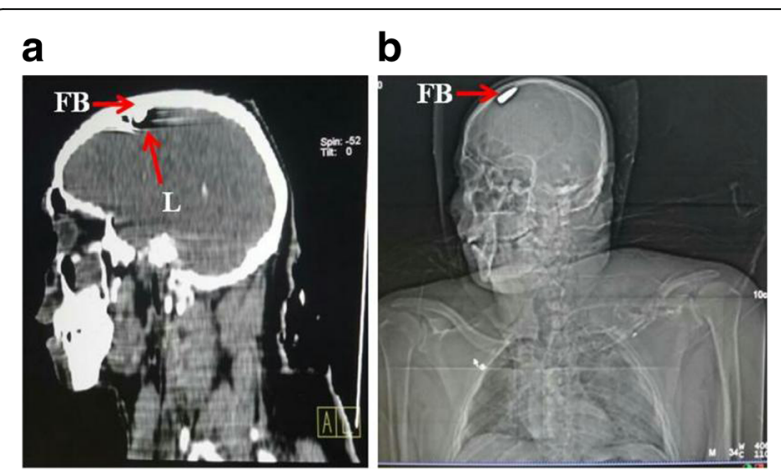

Fig. 2 Gunshot injuries of the head. a MDCT sagittal reformatted image showing the entry wound, wound channel (arrow) with cerebral lacerations (L), and a dense metallic foreign body in the high parietal region (FB). $\mathbf{b}$ Scanogram image showing a dense metallic foreign body in the high parietal region (FB)

entry wounds were detected in all cases by autopsy, but were detected in only 13 of 18 cases by PMCT (K (0.72) $P<0.001$; Figs. 4 and 5; Table 2).

Retained bullets and fragments were detected by autopsy and PMCT in 10 out of 18 cases $(K(1), P<0.001)$. Fractures in thoracic vertebrae were detected in 6 cases by PMCT and in 2 cases by autopsy $(K(0.42), P>0.05)$. Rib fractures were detected in 14 cases by PMCT and in 10 cases by autopsy $(K(0.71), P<0.01$; Figs. 4,5 , and 6 ; Table 2).

Autopsy detected heart lesions with hemopericardium in 4 cases, while PMCT detected this condition in 2 cases $(K(0.43) P<0.05)$. Both autopsy and PMCT detected hemothorax in 16 of 18 cases $(K(1), P<0.001)$. Autopsy detected lung lacerations in 16 cases and PMCT detected this condition in 14 cases $(K(0.87), P<0.001)$. Regarding abdominal injuries, both autopsy and PMCT detected liver lacerations in 10 cases $(K(1), P<0.001)$. Autopsy detected hemoperitoneum and blood vessel lesions in 8 cases, but PMCT detected these conditions in 10 cases ( $K(0.87), P<0.001$; Figs. 7, 8, and 9; Table 2).

\section{Comparison of autopsy and PMCT for detection of cause of death in gunshot injury cases:}

Both PMCT and autopsy could determine cerebral hemorrhage in all cases $(K(1), P<0.001)$. Autopsy determined cerebral lacerations in all 12 cases but PMCT determined this condition in only 6 cases $(K(0.51)$ $P<0.05)$. Pneumocephalus was detected by PMCT in 8 cases but was not detected by autopsy $(K(0), P=1$; Figs. 3 and 4; Table 3).

In cases of multiple gunshot injuries to the chest, pneumothorax with collapsed lungs was detected by PMCT in 8 cases but not by autopsy. Pulmonary lacerations and hemothorax were detected in 8 cases by autopsy and 6 cases by PMCT ( $K(0.73), P<0.01)$. Hemopericardium and heart lesions were determined in 4 cases by autopsy and in 2 cases 

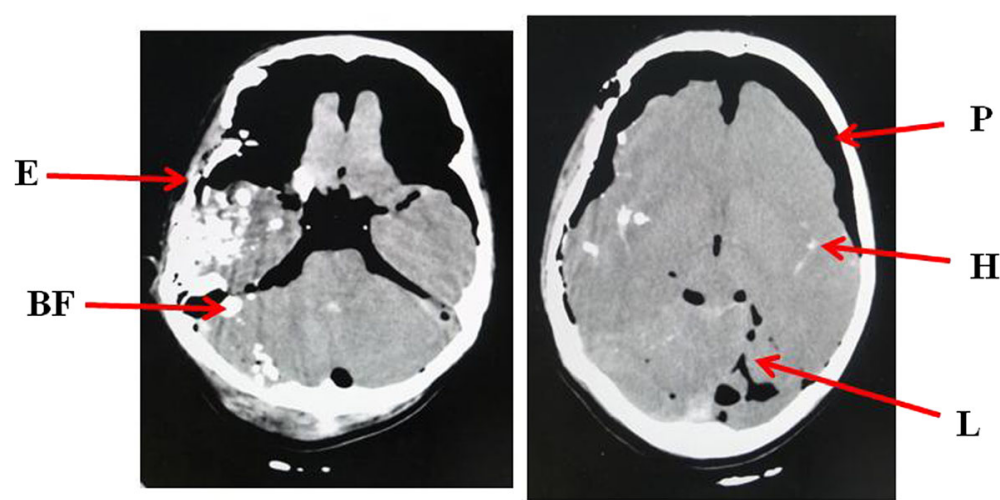

Fig. 3 Gunshot injuries of the head. PMCT axial image showing the exit wound (E) in the vault of the skull with comminuted fractures in the skull bones on the opposite side (right frontal) and intracerebral detached bony fragments (BF). Axial image showing lacerations of the brain (L), pneumocephaly $(\mathrm{P})$, and massive intracerebral hemorrhage $(\mathrm{H})$

by PMCT $(K(0.43) P<0.05)$. In cases of multiple gunshot injuries to the chest and abdomen, pneumothorax was detected in 8 cases by PMCT but was not detected by autopsy $(K(0), P=1)$. Lung lacerations were detected in 8 cases by autopsy and PMCT $(K(1), P<0.001)$. Liver lacerations were detected in 10 cases by autopsy and PMCT $(K(1)$, $P<0.001)$. Hemothorax and hemoperitoneum were detected in 10 cases by PMCT and in 8 cases by autopsy ( $K(0.79), P<0.01$; Figs. 7, 8, and 9; Table 3 ).

\section{Discussion}

The aim of this study was to compare autopsy and PMCT regarding their ability to detect injuries and causes of death in cases of gunshot injury to determine whether PMCT can replace or supplement autopsy. In the present study, the overall parameters were encouraging and showed excellent agreement between autopsy and PMCT regarding detection of injuries and determination of causes of death. Furthermore, PMCT revealed findings that could not be directly observed during autopsy. Leth et al. (2013) investigated the interobserver variation between a radiologist and a forensic pathologist in 994 injury diagnoses obtained by PMCT of 67 traffic fatality victims, and the results were compared with diagnoses obtained by autopsy. They found that CT was better than autopsy in detecting abnormal air accumulations, but autopsy was better than $\mathrm{CT}$ in the detection of organ injuries and aortic ruptures. However, Ruder et al. (2011) reported that post-mortem computed tomography and postmortem magnetic resonance imaging of their case was sufficient to detect the cause of death including internal hemorrhage from laceration of the descending aorta by fragments of the fractured vertebral column leading to internal hemorrhage from the lacerated aorta and finally

Table 1 Degree of agreement between PMCT and autopsy in detection of injuries in cases of firearm injury in the head by Cohen's Kappa test

\begin{tabular}{|c|c|c|c|c|c|c|}
\hline $\begin{array}{l}\text { Detected findings } \\
\text { (number of cadavers }=12\end{array}$ & $N$ & $\begin{array}{l}\text { Cases detected by } \\
\text { autopsy alone } \\
n\end{array}$ & $\begin{array}{l}\text { Cases detected by } \\
\text { PMCT alone } \\
n\end{array}$ & Kappa & Level of agreement & $P$ \\
\hline Wound track: & 12 & 12 & 12 & 1 & Perfect & $<0.001^{* *}$ \\
\hline Inlet wound & 12 & 12 & 12 & 1 & Perfect & $<0.001^{* *}$ \\
\hline Bullet & 2 & 2 & 2 & 1 & Perfect & $<0.001^{* *}$ \\
\hline Bone fragments & 12 & 12 & 12 & 1 & Perfect & $<0.001^{* *}$ \\
\hline \multicolumn{7}{|l|}{ Skull fractures: } \\
\hline Face & 8 & 6 & 8 & 0.67 & Substantial & $<0.01^{*}$ \\
\hline Vault of skull & 8 & 6 & 8 & 0.67 & Substantial & $<0.01^{*}$ \\
\hline \multicolumn{7}{|l|}{ Soft tissue lesions: } \\
\hline Hemorrhage & 12 & 12 & 12 & 1 & Perfect & $<0.001^{* *}$ \\
\hline Lacerations & 12 & 12 & 6 & 0.51 & Moderate & $<0.05^{*}$ \\
\hline Pneumocephalus & 8 & 0 & 8 & 0 & No agreement & $1 \mathrm{NS}$ \\
\hline
\end{tabular}

$\mathrm{N}$ : number of lesions detected; $\mathrm{n}$ : number of cases detected either by autopsy or PMCT; **: highly significant, *: significant, NS: non-significant 


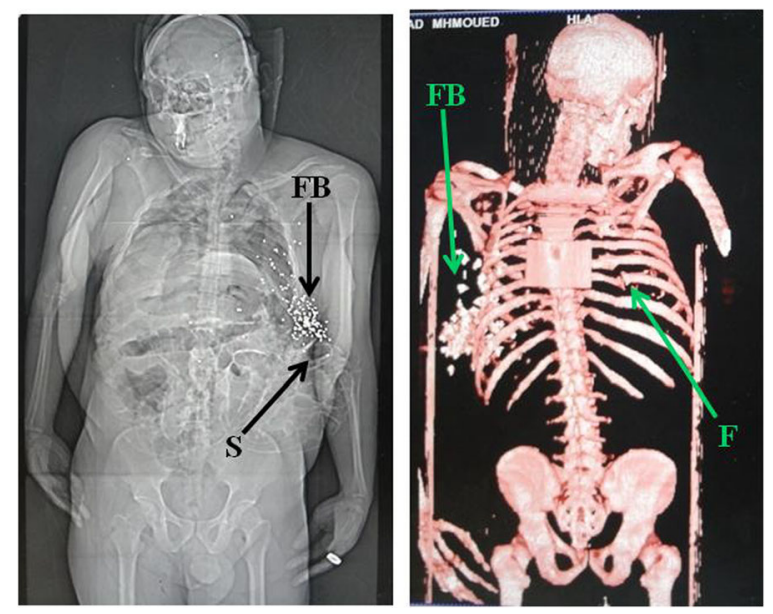

Fig. 4 Multiple gunshot injuries. a PMCT scanogram image showing multiple small, dense metallic foreign bodies (FB; bullet fragments) in the left lung and inside the thoracic cavity and left subcutaneous surgical emphysema (S). b PMCT-3D-volume rendering image showing comminuted fracture (F) of the left ribs (5th, 6th, and 7th) in the chest and multiple, small, dense, metallic foreign bodies (FB; bullet fragments) in the thoracic cavity

cerebral anoxia. This conclusion was accepted by the legal authorities. Lathrop and Nolte (2016) evaluated four potential situations where PMCT might supplant or supplement forensic autopsy. They investigated blunt force and firearm injuries in individuals older than 5 years, all poisoning deaths and traumatic deaths in children 5 years of age and younger. They found that radiologists determined an increased number of injuries in acute cases (traffic fatalities, blunt force, and firearms), similar to our result in which PMCT detected an increased number of injuries in cases involving firearms.

In the present study, PMCT was as valuable as autopsy for detecting the direction of firing, entry wounds with internal beveling, and wound channels. Regarding skeletal injuries, PMCT was superior for detection of comminuted fractures in the vault of the skull, bony fragments, facial bone fractures, rib fractures, and vertebral body fractures.

Previous studies have reported that forensic radiology can differentiate between the entrance and exit wounds, describe the bullet path, and disclose findings that might escape even the most careful observation such as minute bone fragments that can easily be missed in an accurate direct inspection (Pomara et al. 2009; Schnider et al. 2009). A study by Makhlouf et al. (2013) compared the autopsy and CT findings in 47 gunshot victims and reported that entrance wounds were detected concordantly by both CT scan and autopsy in 63 of the 91 penetrating wounds $(69.2 \%)$ and that CT imaging could determine the track of the bullet in up to 62 wounds (72.1\%). Tacchella et al. (2017) presented a case of gunshot wound with an atypical entry wound. They stated that CT images and three-dimensional reconstruction permitted the identification of the correct path of the bullet and excluded the possibility of deviation within this path. Wojciechowski et al. (2016) investigated the role of PMCT in evaluation of decomposed exhumed bodies in comparison with autopsy. They reported that PMCT is particularly useful for three-dimensional reconstruction of

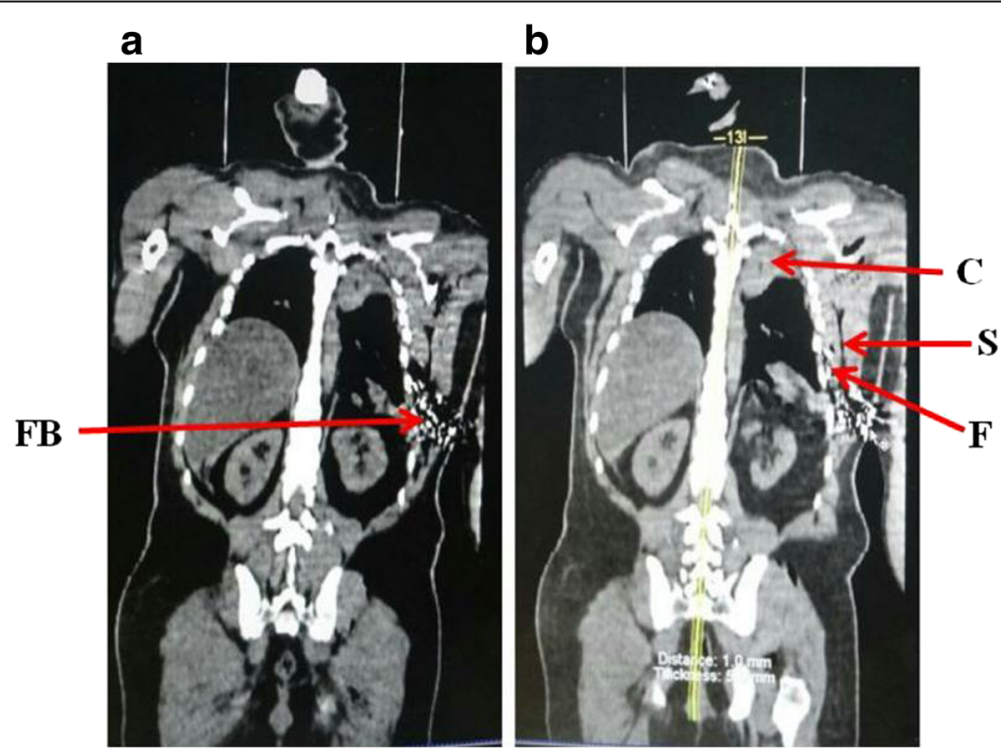

Fig. 5 Multiple gunshot injuries. a PMCT coronal image showing an inlet wound in the middle part of the left side of the chest with multiple small foreign bodies (shots) inside the thoracic cavity (FB). b MDCT coronal image showing laceration of the collapsed left lung, fractures (F) of the left ribs (5th, 6th, and 7th), and subcutaneous surgical emphysema on the opposite side (S) 
Table 2 Degree of agreement between PMCT and autopsy in detection of injuries in cases of multiple firearm injuries in the chest and abdomen by Cohen's Kappa test

\begin{tabular}{|c|c|c|c|c|c|c|}
\hline $\begin{array}{l}\text { Lesion types number } \\
\text { of cadavers }=18\end{array}$ & $N$ & $\begin{array}{l}\text { Detected by } \\
\text { autopsy alone } \\
n\end{array}$ & $\begin{array}{l}\text { Detected by } \\
\text { PMCT alone } \\
n\end{array}$ & Kappa & $\begin{array}{l}\text { Level of } \\
\text { agreement }\end{array}$ & $P$ \\
\hline External wounds & 18 & 18 & 10 & 0.53 & Moderate & $<0.05^{*}$ \\
\hline Multiple inlet wounds & 18 & 18 & 13 & 0.72 & Substantial & $<0.001^{* *}$ \\
\hline Direction of injury & 12 & 12 & 6 & 0.51 & Moderate & $<0.05^{*}$ \\
\hline Wound track & 12 & 12 & 6 & 0.51 & Moderate & $<0.05^{*}$ \\
\hline Retained bullets and fragments & 10 & 10 & 10 & 1 & Perfect & $<0.001^{* *}$ \\
\hline \multicolumn{7}{|l|}{ Thoracic lesions } \\
\hline Rib fractures & 14 & 10 & 14 & 0.71 & Substantial & $<0.001^{* *}$ \\
\hline Heart lesions & 4 & 4 & 2 & 0.43 & Moderate & $<0.05^{*}$ \\
\hline Hemopericarduim & 4 & 4 & 2 & 0.43 & Moderate & $<0.05^{*}$ \\
\hline Lung lacerations & 16 & 16 & 14 & 0.87 & Almost perfect & $<0.001^{* *}$ \\
\hline Fracture of thoracic vertebrae & 6 & 2 & 6 & 0.42 & Moderate & $>0.05$ \\
\hline Pneumothorax & 16 & 0 & 16 & 0 & - & $1 \mathrm{NS}$ \\
\hline Hemothorax & 16 & 16 & 16 & 1 & Perfect & $<0.01^{* *}$ \\
\hline Surgical emphysema & 18 & 0 & 18 & 0 & - & $1 \mathrm{NS}$ \\
\hline \multicolumn{7}{|l|}{ Abdominal lesions } \\
\hline Liver & 10 & 10 & 10 & 1 & Perfect & $<0.001^{* *}$ \\
\hline Blood vessels & 10 & 8 & 10 & 0.87 & Almost perfect & $<0.001^{* *}$ \\
\hline Hemoperitoneum & 10 & 8 & 10 & 0.87 & Almost perfect & $<0.001^{* *}$ \\
\hline
\end{tabular}

$\mathrm{N}$; total number of lesions detected; $\mathrm{n}$ : number of cases detected either by autopsy or PMCT; **: highly significant; *: significant, NS: non-significant

bony structures, allowing visualization of fractures and displacement that may provide clues to the injury mechanism.

PMCT was found to be more reliable in detection of gas accumulations such as pneumothorax, surgical emphysema, and pneumocephalus (these findings were not detected by autopsies where the special dissection technique was not part of our routine procedures). Similar

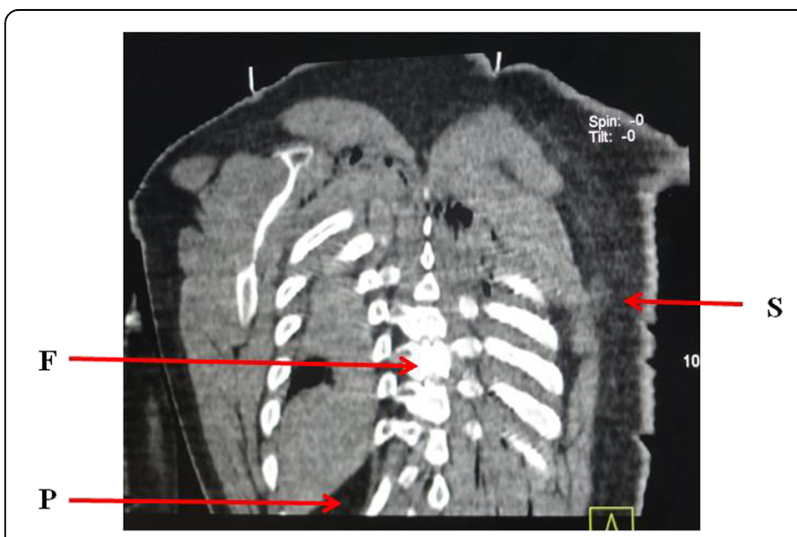

Fig. 6 PMCT coronal image showing pneumomediastinum (P), right side subcutaneous surgical emphysema (S), and fractures (F) in the 4th and 5th thoracic vertebrae (F) findings were reported by previous studies (Schnider et al. 2009; Le Blanc-Louvry et al. 2013; Maiese et al. 2014; Leth 2015). Le Blanc-Louvry et al. (2013) investigated the concordance between PMCT and forensic autopsy in detecting lesions according to different anatomical regions and the efficacy of PMCT in showing lethal lesions. They reported that PMCT provides images with excellent sensitivity for detection of bone fractures and the presence of gas. Lathrop and Nolte (2016) reported that although external contusions and lacerations were the most commonly missed findings on PMCT examination, autopsy missed 17 to $21 \%$ of injuries that could only be detected by PMCT, including pneumothorax and pneumocephalus and vertebral body fractures, in cases of death due to firearm injuries, pediatric trauma, or blunt force injuries.

The detection of foreign bodies is a cardinal aspect of forensic radiology. The present study reported that PMCT was a superior tool for the visualization and localization of bullets and fragments before autopsy. This is consistent with the current literature in which several authors have stated that PMCT exhibits a distinct advantage for ballistic analysis (Andenmatten et al. 2008; Wojciechowski et al. 2016). In the same context, Celik et al. (2015) stated that the presence and localization of foreign bodies such as a 


\section{$\mathbf{L}$}

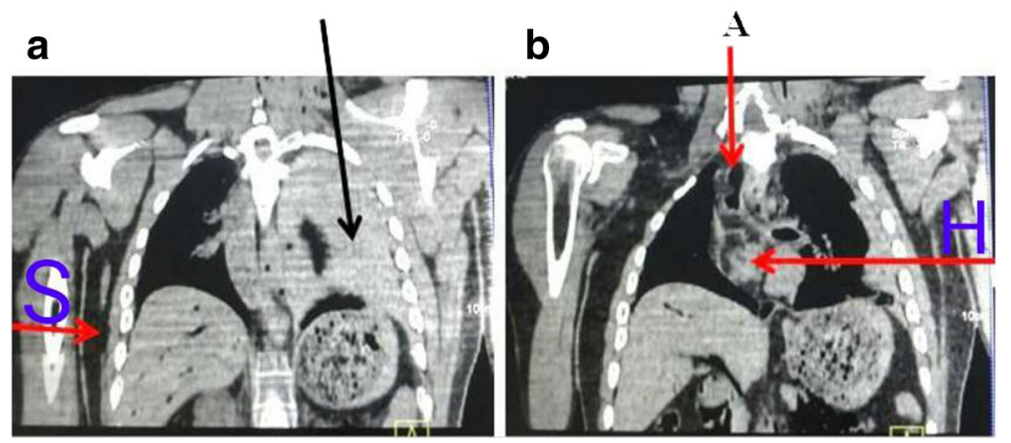

Fig. 7 Multiple gunshot injuries. a PMCT coronal image showing lacerations (L) in left lung and bilateral subcutaneous surgical emphysema (S). b PMCT coronal image showing air in the ascending aorta $(\mathrm{A})$ and hemopericardium $(\mathrm{H})$

bullet, knife blade, medical implants or drugs hidden in body cavities can be accurately determined with density measurements on PMCT before opening the body. Furthermore, PMCT facilitates the appropriate removal of foreign bodies in an autopsy. Kirchhoff et al. (2016) reported that defining the exact location and three-dimensional display of the fragments and the evaluation of damage to the surrounding tissue are some of the great advantages of PMCT.

In cases of multiple gunshot lesions, we found autopsy to be somewhat better for detecting external wounds, multiple entry wounds, wound channels, direction of injury, heart lesions with hemopericardium, and lung lacerations, all of which are directly inspected during autopsy. PMCT does not show the lesions with the same resolution as can be obtained with the naked eye. Lathrop and Nolte (2016) stated that trajectories were more challenging to assess with multiple wounds, with only $44-58 \%$ correctly

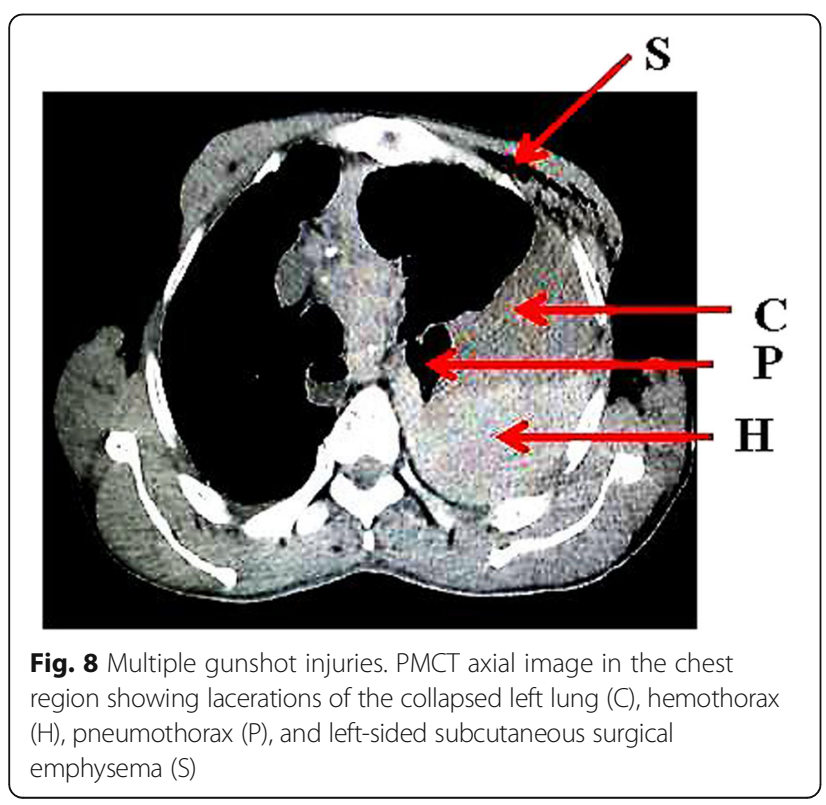

identified due to the difficulty in adequately describing the trajectories, and not advisable to supplant autopsy with PMCT.

Both autopsy and PMCT determined cerebral hemorrhage as a cause of death in all cases of gunshot injury to the head. Only PMCT could diagnose pneumocephalus. Autopsy was somewhat better for the detection of cerebral lacerations, whereas PMCT detected cerebral lacerations in $50 \%$ of cases (moderate agreement). These results coincided with those of Le Blanc-Louvry et al. (2013). Also, Makhlouf et al. (2013) reported in their study that CT scan was of limited value in demonstrating contusions of the brain.

This study showed $87-100 \%$ agreement between PMCT and autopsy for the detection of the cause of death in cases of multiple firearm injuries in the chest and abdomen that involved hemothorax, hemoperitoneum, and pulmonary or liver lacerations. Moreover, only PMCT detected pneumothorax and surgical emphysema that were determined to be out of the scope of routine autopsies.

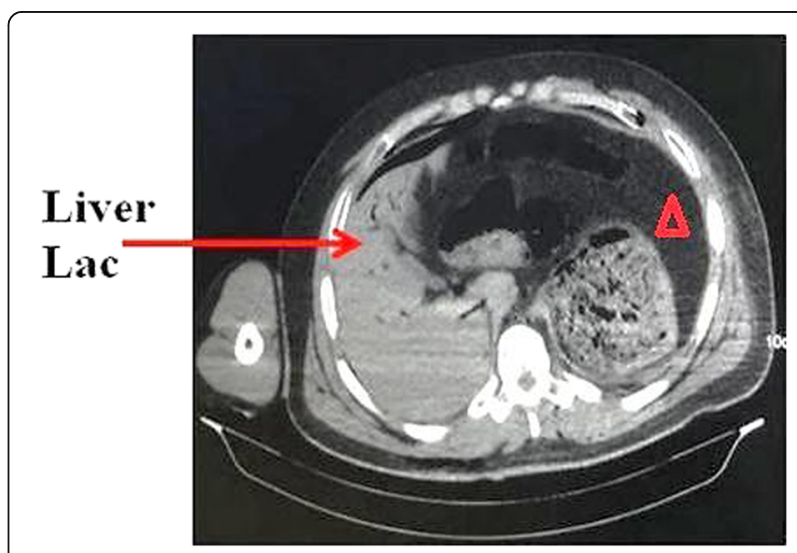

Fig. 9 Multiple gunshot injuries. PMCT axial image showings liver lacerations (arrow) and hemoperitoneum $(\Delta)$ 
Table 3 Degree of agreement between PMCT and autopsy in detection of causes of death in firearm injuries by Kappa test

\begin{tabular}{|c|c|c|c|c|c|c|c|c|c|}
\hline \multirow{2}{*}{$\begin{array}{l}\text { Region of death } \\
\text { causing injury }\end{array}$} & \multirow[t]{2}{*}{ Causes of death } & \multirow[t]{2}{*}{$N$} & \multicolumn{2}{|c|}{ Findings in autopsy } & \multicolumn{2}{|c|}{ Findings in PMCT } & \multirow[t]{2}{*}{ Kappa } & \multirow{2}{*}{$\begin{array}{l}\text { Level of } \\
\text { agreement }\end{array}$} & \multirow[t]{2}{*}{$P$} \\
\hline & & & No & $\%$ & No & $\%$ & & & \\
\hline \multirow[t]{3}{*}{ Head Cases $=12$} & Brain lacerations, & 12 & 12 & $100 \%$ & 6 & $50 \%$ & 0.51 & Moderate & $<0.05^{*}$ \\
\hline & Hemorrhage & 12 & 12 & $100 \%$ & 12 & 100 & 1 & Perfect & $<0.001^{* *}$ \\
\hline & Pneumocephalus & 8 & 0 & $0 \%$ & 8 & $80 \%$ & 0 & - & $1 \mathrm{NS}$ \\
\hline \multirow[t]{3}{*}{ Chest Cases $=8$} & Pneumothorax & 8 & 0 & 0 & 8 & 100 & 0 & - & $1 \mathrm{NS}$ \\
\hline & $\begin{array}{l}\text { Lung lacerations, } \\
\text { hemothorax }\end{array}$ & 8 & 8 & $75 \%$ & 6 & $100 \%$ & 0.72 & Substantial & $<0.01^{* *}$ \\
\hline & $\begin{array}{l}\text { Hemopericardium, } \\
\text { heart lesions }\end{array}$ & 4 & 4 & $100 \%$ & 2 & $50 \%$ & 0.43 & Moderate & $<0.05^{*}$ \\
\hline \multirow{4}{*}{$\begin{array}{l}\text { Chest and abdomen } \\
\text { Cases }=10\end{array}$} & Pneumothorax & 8 & 0 & $0 \%$ & 8 & $80 \%$ & 0 & - & $1 \mathrm{NS}$ \\
\hline & Lung lacerations & 8 & 8 & $100 \%$ & 8 & $100 \%$ & 1 & Perfect & $<0.001^{*}$ \\
\hline & Liver lacerations & 10 & 10 & $100 \%$ & 10 & $100 \%$ & 1 & Perfect & $<0.001^{* *}$ \\
\hline & Hemothorax and hemoperitoneum & 10 & 8 & $80 \%$ & 10 & $100 \%$ & 0.79 & Substantial & $<0.01^{* *}$ \\
\hline
\end{tabular}

$\mathrm{N}$ : number of cases showing the lesion, No: number of cases with detected lesion either by autopsy or by PMCT, *: significant, **: highly significant, NS: non-significant

These results coincided with those of Makhlouf et al. (2013) and Lathrop and Nolte (2016).

Lathrop and Nolte (2016) reported that autopsy and PMCT can separately arrive at the same cause of death for a given decedent. In $85 \%$ of blunt force injury deaths, 99.5\% of firearm fatalities, $81.4 \%$ of pediatric trauma deaths, and up to $78 \%$ of drug poisoning deaths, the cause of death assigned by PMCT was correct and the same as that assigned by autopsy. Moreover, PMCT resulted in a significantly higher mean number of injuries detected per region than autopsy in the head, chest, abdomen, and extremities.

\section{Conclusion}

The injuries and cause of death assigned by PMCT were determined to be correct and consistent with those assigned by autopsy in the majority cases. Moreover, imaging could be better than autopsy for the diagnosis of some fractures and for detection of pneumothorax and pneumocephalus. PMCT could be a good complementary tool for the determination of the cause of death and for localization and diagnosis of different types of lesions in gunshot injuries. In the majority of cases included in this study, PMCT could supplant autopsy due to its excellent results, especially for single gunshot injuries. Although PMCT was a valuable tool for assessment of firearm fatalities, further studies involving a larger number of cadavers with different circumstances and other techniques are needed to confirm our results.

\section{Abbreviations}

$\mathrm{CT}$ : Computed tomography; PMCT: Postmortem multislice computed tomography

\section{Availability of data and materials}

The datasets supporting the conclusions of this article are included within the article.

\section{Authors' contributions}

Dr. ESA contributed to the study design, the idea, data analysis interpretation of results, writing, and final revision of the paper. Dr. MEB was responsible for the practical part of the research, data analysis, and interpretation of results assist in writing the paper. Prof. MHA was responsible of the idea and assisted in the design of the research and revision of the paper. Dr. IAA was responsible for the practical part of the research. All authors read and approved the final manuscript.

\section{Ethics approval and consent to participate}

The study was performed after approval from the Institutional Review Board (IRB) of the Faculty of Medicine, Zagazig University, Egypt (reference no. 1939).

\section{Consent for publication}

Not applicable.

\section{Competing interests}

The authors declare that they have no competing interests.

\section{Publisher's Note}

Springer Nature remains neutral with regard to jurisdictional claims in published maps and institutional affiliations.

\section{Author details}

'Department of Forensic Medicine \& Clinical Toxicology, Faculty of Medicine, Zagazig University, Zagazig, Egypt. ²Forensic Medicine Authority, Zagazig, Egypt. ${ }^{3}$ Radiology Department, Faculty of Medicine, Zagazig University, Zagazig, Egypt.

Received: 13 March 2018 Accepted: 6 August 2018

Published online: 20 August 2018

\section{References}

Andenmatten MA, Thali MJ, Kneubuehl BP, Oesterhelweg L, Ross S, Spendlove D, Bolliger SA (2008) Gunshot injuries detected by post-mortem multislice computed tomography (MSCT): a feasibility study. Leg Med (Tokyo) 10:287-292

Celik M, Butun C, Fatma Beyaztas Y, Gumus Cl, Oztoprak I (2015) Importance of multi-slice computed tomography for autopsy: single center experience medicine science 4: 2039-56

DiMaio VJ (2002) Gunshot wounds: practical aspects of firearms, ballistics, and forensic techniques, 2nd edn. CRC press; Boca Raton, New York

Dirnhofer R, Jackowski C, Thali MJ et al (2006) Virtopsy: minimally invasive, imaging-guided virtual autopsy. RadioGraphics 26:1305-1333

Kirchhoff SM, Scaparra EF, Grimm J, Scherr M, Graw M, Reiser MF, Peschel O (2016) Postmortem computed tomography (PMCT) and autopsy in deadly gunshot wounds - a comparative study Int J Legal Med 130: 819-826 
Lathrop SL, Nolte KB (2016) Utility of postmortem X-ray computed tomography (CT) in supplanting or supplementing medicolegal autopsies. From https:// www.ncjrs.gov/pdffiles1/nij/grants/; 249949

Le Blanc-Louvry I, Thureau S, Duval C, Papin-Lefebvre F, Thiebot J, Dacher JN, Gricourt C, Touré E, Proust B (2013) Post-mortem comuted tomography compared to forensic autopsy findings: a French experience. Eur Radiol 23: 1829-1835

Leth PM (2015) Computed tomography in forensic medicine. Danish Med J 62:1-26 Leth PM, Struckmann H, Lauritsen J (2013) Interobserver agreement of the injury diagnoses obtained by postmortem computed tomography of traffic fatality victims and a comparison with autopsy results. Forensic Sci Int 225:15-19

Lo Re G, Vernuccio F, Galfano MC, Picone D, Milone L, La Tona G, Argo A, Zerbo $S$ et al (2015) Role of virtopsy in the post-mortem diagnosis of drowning. La Radiologia Medica 120:304-308. https://doi.org/10.1007/s11547-014-0438-4

Madea B, Argo A (2014): Certification of death: external postmortem examination; Handbook of Forensic Medicine, Whiley, Ch (6): 57-74 https://doi.org/10. 1002/9781118570654.ch6

Maiese A, Gitto L, De Matteis A, Panebianco V, Bolino G (2014) Post mortem computed tomography: useful or unnecessary in gunshot wounds deaths? Two case reports. Leg Med (Tokyo) 16:357-363

Makhlouf F, Scolan V, Ferretti G, Stahl C, Paysant F (2013) Gunshot fatalities: correlation between post-mortem multi-slice computed tomography and autopsy findings: a 30-months retrospective study. Leg Med (Tokyo). 15(3): 145-148. https://doi.org/10.1016/j.legalmed.2012.11.002

Pomara C, Fineschi V, Scalzo G et al (2009) Virtopsy versus digital autopsy: virtual autopsy. Radiol Med 114:1367-1382

Roberts IS, Benamore RE, Benbow EW, Lee SH, Harris JN, Jackson A et al (2012) Post-mortem imaging as an alternative to autopsy in the diagnosis of adult deaths: a validation study. Lancet 379:136-142

Ruder TD, Hatch GM, Thali MJ, Fischer N (2011) One small scan for radiology, one giant leap for forensic medicine - Post-mortem imaging replaces forensic autopsy in a case of traumatic aortic laceration. Legal Med 13(1):41-43

Rutty GN, Brogdon G, Dedouit F (2013) Terminology used in publications for post-mortem cross-sectional imaging. Int I Legal Med 127:465-466

Schnider J, Oesterhelweg L, Bolliger SA et al (2009) Injuries due to sharp trauma detected by post-mortem multislice computed tomography (MSCT): a feasibility study. Leg Med (Tokyo) 11:4-9

Sieswerda Hoogendoorn T, Soerdjbalic-Maikoe V, De Bakker K, van Rijn R (2014) Postmortem CT compared to autopsy in children; concordance in a forensic setting. Int J Legal Med 128:957-965

Simons D, Sassenberg A, Schlemmer H-P, Yen K (2014) Forensic imaging for causal investigation of death. Korean J Radiol 15:205-209

Tacchella T, Ventura F, Cittadini G, Nosenzo F, Molinelli A (2017) The importance of computer tomography-imaging in a case of a gunshot wound with an atypical entrance wound. J Forensic Radiol Imaging 10:1-4

Tartaglione T, Filograna L, Roiati S, Guglielmi G, Colosimo C, Bonomo L (2012) Importance of 3D-CT imaging in single-bullet cranioencephalic gunshot wounds. Radiol Med 117(3):461-470

Westphal SE, Apitzsch J, Penzkofer T, Mahnken AH, Knuchel R (2012) Virtual CT autopsy in clinical pathology: feasibility in clinical autopsies. Virchows Arch 461:211-219

Wichmann D, Obbelode F, Vogel H (2012) Virtual autopsy as an alternative to traditional medical autopsy in the intensive care unit: a prospective cohort study. Ann Intern Med 156:123-130

Wojciechowski A, Fudalej M, Skowronek P (2016) Assessment of head gunshot wounds by means of post-mortem computed tomography in exhumed anonymous cadaver. BJR Case Rep 2(4). https://doi.org/10.1259/bjrcr.20150304

\section{Submit your manuscript to a SpringerOpen ${ }^{\circ}$ journal and benefit from:}

- Convenient online submission

- Rigorous peer review

- Open access: articles freely available online

- High visibility within the field

- Retaining the copyright to your article

Submit your next manuscript at $\boldsymbol{\nabla}$ springeropen.com 